\title{
Infant Health Matters
}

Susan Hepworth, Mitchell Goldstein, MD, MBA, CML

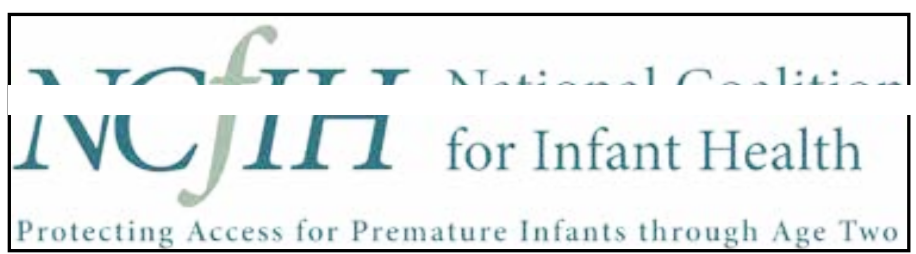

The National Coalition for Infant Health is a collaborative of more than 200 professional, clinical, community health, and family support organizations focused on improving the lives of premature infants through age two and their families. NCfIH's mission is to promote lifelong clinical, health, education, and supportive services needed by premature infants and their families. NCfIH prioritizes safety of this vulnerable population and access to approved therapies.

\section{Q:Why is it important that medications and devices be devel- oped specifically for infants?}

When it comes to medical innovation, not all patients are the same. The preterm babies I care for in the NICU, for example, need the highest level of care. They are not "tiny adults." Yet, they are often subjected to smaller doses of "adult" medication or smaller versions of adult devices. This can be dangerous. Measurement errors and inaccurate device readings can lead to poor health outcomes. I know firsthand that we need innovative technologies tailored to their size and weight for the health and safety of my tiny patients.

\section{Q: What is one example of innovation improving infant health care?}

The pulse oximeter. Today, most people know it as a tiny device that slides over your finger and uses light to measure blood oxygen levels. But as recently as the early 1990s, neonatologists had to treat newborn patients using a conventional oximeter, which was developed for adults. These monitors were unreliable and inadvertently led to some preterm babies receiving too much oxygen, causing blindness in some cases. There were other issues as well. Infants' motion and decreased perfusion sometimes prevented these monitors from reading. When the first pulse oximeter adapted for neonates was developed, a patient I was caring for became the first life of many saved.

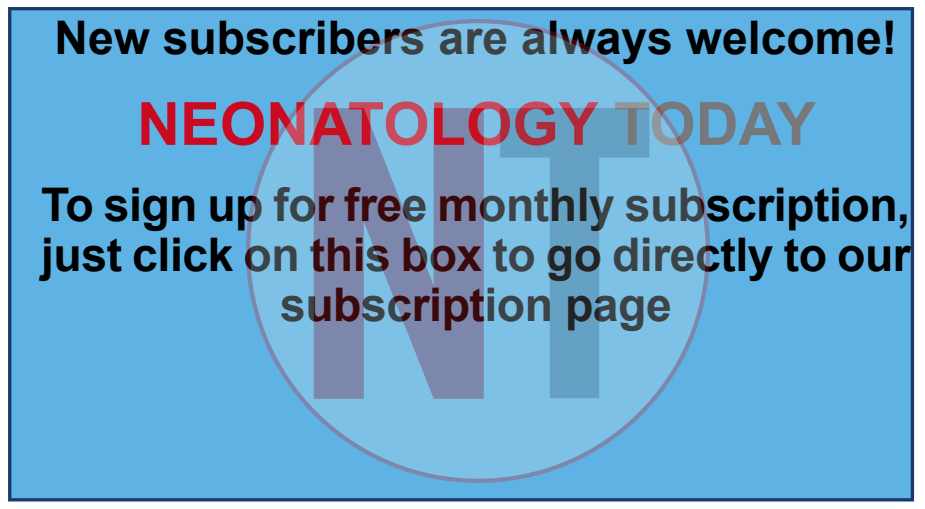

Tiny patients need innovative technologies tailored to their size and weight. Other medical devices, such as ventilators and tubing designed for infants, also prevent avoidable illness and death.

\section{Q: Do you recall a time when safety was critical for a patient's survival?}

Yes, on numerous occasions. I think about this patient who became the first life saved by a pulse oximeter designed for infants. Back then, the oximeter was part of a study, not yet widely accepted and distributed in hospitals. My patient was in critical condition, and the conventional pulse oximeter my team and I were using repeatedly failed to provide an accurate reading of blood oxygen levels. I made a crucial decision to use the "experimental" monitor, which had important modifications to enhance infant safety, and it worked, ultimately saving the infant's life.

\section{Q: How can policymakers encourage the development of more medications and devices for infants?}

Policymakers have a lot of options for incentivizing drug development in areas of high need. That includes research grants, patent extensions, tax credits, or regulatory incentives like priority review vouchers. We need policymakers to use these tools to encourage optimal infant care and protection. But policies also have to allow for infants to access these drugs and devices once they are developed. For example, at some hospitals, administrators are mandated to purchase medical products from specific manufacturers without considering performance and outcomes data. This can limit access and discourage smaller companies from innovating for infants especially those at greatest risk for disparity.

"For example, at some hospitals, administrators are mandated to purchase medical products from specific manufacturers without considering performance and outcomes data. This can limit access and discourage smaller companies from innovating for infants especially those at greatest risk for disparity."

Encouraging competition, promoting innovation, and ensuring access can go a long way toward furthering devices and medications for infants-and saving lives.

\section{Disclosure: No relevant disclosures noted}

NT 

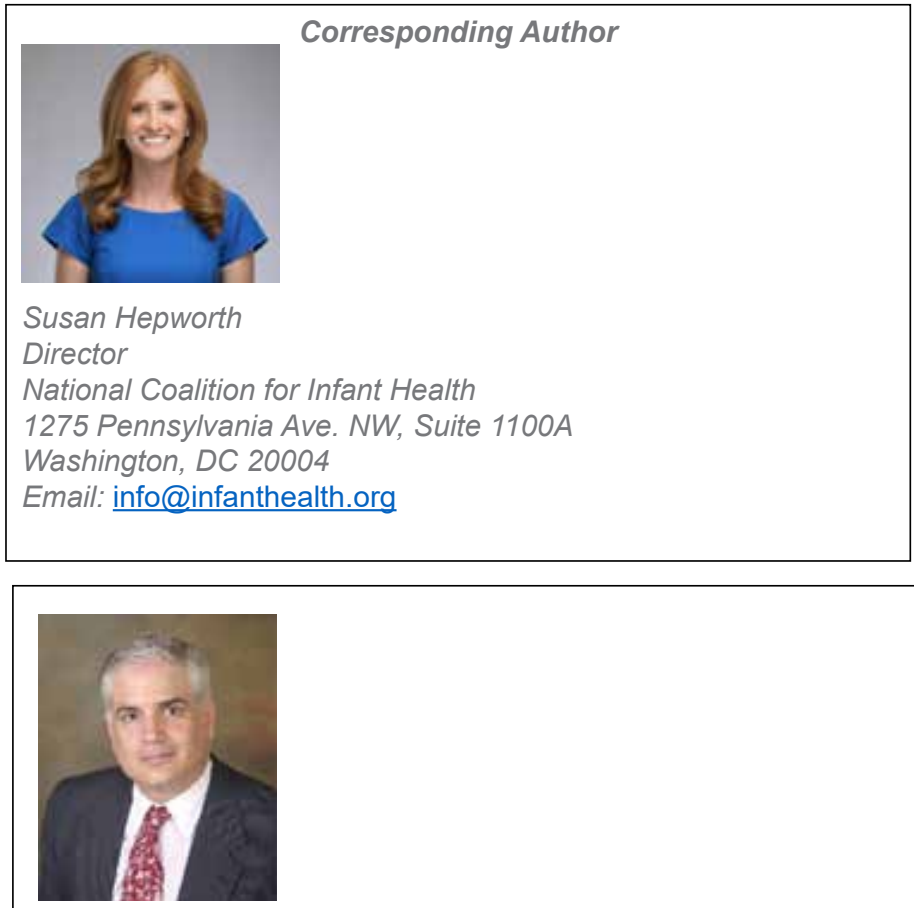

Mitchell Goldstein, MD, MBA, CML

Professor of Pediatrics

Loma Linda University School of Medicine

Division of Neonatology

Department of Pediatrics

Email: mgoldstein@llu.edu

National Coalition for Infant Health Values (SANE)

Safety. Premature infants are born vulnerable. Products, treatments and related public policies should prioritize these fragile infants' safety.

Access. Budget-driven health care policies should not preclude premature infants' access to preventative or necessary therapies.

Nutrition. Proper nutrition and full access to health care keep premature infants healthy after discharge from the NICU.

Equality. Prematurity and related vulnerabilities disproportionately impact minority and economically disadvantaged families. Restrictions on care and treatment should not worsen inherent disparities.

\section{Which Infants are More Vulnerable to Respiratory Syncytial Virus?}

\author{
RSV is a respiratory virus with cold-like symptoms that causes \\ 90,000 hospitalizations and 4,500 deaths per year in children \\ 5 and younger. It's 10 times more deadly than the flu. \\ For premature babies with fragile immune systems and \\ underdeveloped lungs, RSV proves especially dangerous.
}

But risk factors associated with RSV don't touch all infants equally.*

\begin{tabular}{|c|c|c|}
\hline Caucasian Babies & Risk Factor & $\begin{array}{c}\text { African American } \\
\text { Babies }\end{array}$ \\
\hline $11.6 \%$ & Prematurity & $18.3 \%$ \\
\hline $58.1 \%$ & Breastfeeding & $50.2 \%$ \\
\hline $7.3 \%$ & $\begin{array}{l}\text { Low Birth } \\
\text { Weight }\end{array}$ & $11.8 \%$ \\
\hline $60.1 \%$ & Siblings & $71.6 \%$ \\
\hline $1 \%$ & $\begin{array}{l}\text { Crowded } \\
\text { Living } \\
\text { Conditions }\end{array}$ & $3 \%$ \\
\hline
\end{tabular}

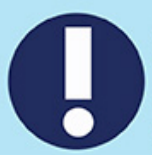
AFRICAN AMERICAN BABIES bear the brunt of RSV Yet the American Academy of Pediatrics' restrictive new guidlines limit their access to RSV preventative treatment, increasing these babies' risk.

\section{$\Omega$

NEONATOLOGY TODAY is interested in publishing manuscripts from Neonatologists, Fellows, NNPs and those involved in caring for neonates on case studies, research results, hospital news, meeting announcements, and other pertinent topics.

Please submit your manuscript to: LomaLindaPublishingCompany@gmail.com 